\title{
CÁLCULO DE PARÂMETROS PARA O PROBLEMA DE LOCALIZAÇÃo DE ESCOLAS NO MUNICIPIO DE MACAÉ
}

\author{
Luize de Magalhães Moura \\ Universidade Federal Fluminense - UFF/PURO \\ Rua Recife, S/N - Jardim Bela Vista, Rio das Ostras \\ luizemoura@gmail.com \\ Anibal Alberto Vilcapoma Ignacio \\ Universidade Federal Fluminense - UFF/PURO \\ Rua Recife, S/N - Jardim Bela Vista, Rio das Ostras \\ anibalvilcapoma@gmail.com
}

\begin{abstract}
Resumo
Apesar de o Brasil ter obtido progressos expressivos no campo da educação nas últimas décadas, o país ainda enfrenta a dificuldade de atendimento à grande parcela da população. Muito se deve ao processo de urbanização desordenado, com isso existe a dificuldade do atendimento as áreas localizadas fora da mancha urbana, o que impacta diretamente a rede escolar. Em Macaé o impacto é grave, uma vez que este município conhecido como a capital do petróleo, também é o município brasileiro que mais cresce e encontra-se despreparado para os impactos resultantes de intensos processos migratórios. Investir fortemente na educação infantil, conferindo centralidade no atendimento das crianças de 0 a 5 anos, é a tarefa e o grande desafio do município. Para isso, é essencial o levantamento detalhado da demanda por creche e pré-escola, de modo a materializar o planejamento da expansão e a melhoria das unidades já existentes. No presente artigo é feita uma delimitação das questões referentes à infraestrutura da área de educação, de modo que ao final se tenha uma boa quantidade de dados que possam ser tratados matematicamente e contribuam para a elaboração de uma proposta metodológica consistente.
\end{abstract}

Palavras-Chaves: $\quad$ Programação Matemática; Medianas; Modelagem; Educação; Macaé;

\begin{abstract}
Although Brazil has achieved significant progress in education in recent decades, the country still faces the difficulty of compliance with most of the population. Much is due to the disorderly urbanization process, therefore there is the difficulty of the service areas located outside the urban area, which directly impacts the school network. In Macaé the impact is severe, since this city known as the oil capital, is also the Brazilian city's fastest growing and is unprepared for the impacts of intensive migration processes. Invest heavily in early childhood education, giving centrality in the care of children 0-5 years, it is the task and the challenge of the municipality. Therefore, it is essential the detailed survey of the demand for day care and pre-school, in order to materialize the planning of expansion and improvement of existing units. In this paper a definition of matters relating to the infrastructure of the area of education, so that in the end it has a good amount of data that can be treated mathematically and contribute to the development of a consistent methodological approach.

Keywords:

Mathematical Programming; Median Model; Modeling; Education; Macaé;
\end{abstract}




\section{INTRODUÇÃO}

A principal característica da educação brasileira, no século 20, era a massificação do acesso ao ensino fundamental e médio, sem levar em consideração a qualidade educacional [1]. Sendo assim, acreditava-se que os problemas centrais da educação brasileira ocorriam pela falta de escolas, inclusive a ausência das crianças nas unidades escolares. Enquanto ainda se falava em construir mais escolas, o país começava a enfrentar, pela primeira vez, problemas de salas de aula vazias. Tal desequilíbrio relacionava-se à redução demográfica e migratória, durante a década de 1980 [2].

Em contrapartida, o Brasil registrou avanços significativos, no campo da educação, ao longo dos últimos 15 anos [3]. No entanto, ainda hoje apresenta uma série de desafios para chegar ao progresso pleno, neste campo. De acordo com o estudo conduzido pelo Banco Mundial [4] o Brasil obteve algum progresso expressivo e um dos fatores responsáveis para tanto, foi o desempenho dos estudantes brasileiros em matemática, que aumentou em 52 pontos, desde 2000, além do aumento geral de pontuações, de 368 a 401, - a terceira maior pontuação já registrada pela OCDE.

Apesar destas poucas vitórias, o país ainda permanece abaixo da média dos países da OCDE e de países orientais [4].

Com o PDE, o MEC introduziu um novo indicador para aferir o nível de desenvolvimento da Educação Básica no país, o Índice de Desenvolvimento da Educação Básica (IDEB) que agrega, em um só número (variando de 0 a 10), a aprovação (fluxo escolar) e a aprendizagem para cada ciclo de aprendizagem, obtido do Censo Escolar do ano de avaliação e do Prova Brasil, respectivamente [3]. Mesmo com os notórios avanços que a educação vem fazendo ao longo dos anos, existe ainda muitos desafios a serem conquistados.

Diversos municípios brasileiros têm enfrentado o processo acelerado de urbanização, no qual não é devidamente acompanhado pela rede de serviços, que aos poucos, vai deixando de atender aos desejos e necessidades de grande parcela da população, inclusive ao não provir acesso universal na maioria dos casos [5] em extensas áreas, bem como em todas as áreas periféricas ou favelizadas das grandes metrópoles [6]. Este processo de urbanização resulta em problemas relativos à ocupação desordenada e irracional do solo urbano com a existência de áreas totalmente vazias ou pouco adensadas no interior das médias e grandes cidades, ao mesmo tempo em que surgem ocupações de áreas mais distantes, faz transparecer a dissociação entre transporte e ocupação do solo e onera e dificulta o atendimento das áreas localizadas fora da mancha urbana [5] que afetam a distribuição espacial o que impacta diretamente na rede escolar.

No que tange ao município de Macaé, o quadro acima é ainda mais grave, uma vez que este, sendo conhecido como a capital do petróleo, também é o município brasileiro que mais cresce, desde a década de 1970 até hoje. Desde então, Macaé se encontra despreparado para os impactos resultantes de intensos processos migratórios, aumentando a sua população dramaticamente em 440\%, em 36 anos, passando de 47 mil habitantes, em 1974, para 206 mil, em 2010 [5].

Investir fortemente na educação infantil, conferindo centralidade no atendimento das crianças de 0 a 5 anos, é a tarefa e o grande desafio do município. Para isso, é essencial o levantamento detalhado da demanda por creche e pré-escola, de modo a materializar o planejamento da expansão, inclusive com os mecanismos de busca ativa de crianças em âmbito municipal, projetando o apoio do estado e da União para a expansão da rede física (no que se refere ao financiamento para reestruturação e aparelhagem da rede) [7].

Um dos problemas em questão surge quando a rede de ensino municipal não atende às demandas de alunos da educação infantil e fundamental por vagas próximas as suas residências, podendo ser pela quantidade insuficiente de escolas ou pela má localização das mesmas em relação à distribuição territorial da população [8] fazendo com que os alunos tenham que se deslocar para escolas distantes de sua residência. 
Para o desenvolvimento de um modelo matemático que permita equacionar as variáveis envolvidas em uma unidade de educação infantil, é necessário se determinar como ela deve estar estruturada [9]. Para isto, não só as regulamentações oficiais devem ser consideradas, como também a análise da realidade que será considerada como referência. Isso se justifica pela falta de regulamentações específicas acerca das unidades escolares.

No presente artigo é feita uma delimitação das questões referentes à infraestrutura da área de educação, de modo que ao final se tenha uma boa quantidade de dados que possam ser tratados matematicamente e contribuam para a elaboração de uma proposta metodológica consistente.

Para isto, utiliza-se a legislação vigente e o levantamento de dados por pesquisa direta no município de Macaé, visto que este é um município que possui uma demanda dinâmica por escolas, motivada pelo processo migratório vigente.

$\mathrm{O}$ artigo está estruturado em cinco seções. A primeira introduz o tema. A segunda apresenta o problema e o modelo proposto para solucioná-lo. A terceira traz as deliberações a respeito do cálculo de custo aluno, que tornam possível criar um parâmetro para apoiar políticas para a construção de unidades escolares, constituindo o arcabouço teórico do modelo matemático a ser construído; finalmente, a quarta seção apresenta as conclusões e recomendações do trabalho.

\section{METRICAS UTILIZADAS NO ENSINO BÁSICO BRASILEIRO E PROPOSTAS}

De acordo com a Lei de Diretrizes e de Bases da Educação Nacional (BRASIL, 1996) é assegurada a educação básica obrigatória e gratuita dos 4 (quatro) aos 17 (dezessete) anos de idade, organizada da seguinte forma: (Redação dada pela Lei $\mathrm{n}^{\circ} 12.796$, de 2013)

a) pré-escola; (Incluído pela Lei no 12.796, de 2013)

b) ensino fundamental; (Incluído pela Lei n 12.796, de 2013)

No Artigo 11, que tange as responsabilidades municipais, os Municípios incumbir-seão dentre outras atribuições:

$\mathrm{V}$ - Oferecer a educação infantil em creches e pré-escolas, e, com prioridade, o ensino fundamental, permitida a atuação em outros níveis de ensino somente quando estiverem atendidas plenamente as necessidades de sua área de competência e com recursos acima dos percentuais mínimos vinculados pela Constituição Federal à manutenção e desenvolvimento do ensino.

VI - Assumir o transporte escolar dos alunos da rede municipal. (Incluído pela Lei $\mathrm{n}^{\circ}$ 10.709, de 31.7.2003)

Parágrafo único. Os Municípios poderão optar, ainda, por se integrar ao sistema estadual de ensino ou compor com ele um sistema único de educação básica.

No que tange a educação infantil, de acordo com o Artigo 30. A educação infantil será oferecida em:

I - Creches, ou entidades equivalentes, para crianças de até três anos de idade;

II - Pré-escolas, para as crianças de 4 (quatro) a 5 (cinco) anos de idade. (Redação dada pela Lei $\mathrm{n}^{\circ}$ 12.796, de 2013).

O ensino fundamental obrigatório, com duração de 9 (nove) anos, gratuito na escola pública, iniciando-se aos 6 (seis) anos de idade. (Artigo 32).

Em um documento posterior, Parâmetros Básicos de Infraestrutura para Instituições de Educação Infantil [10], são feitas sugestões aos dirigentes municipais de educação buscando ampliar os diferentes olhares sobre o espaço, visando construir o ambiente físico destinado à Educação Infantil. O espaço lúdico infantil deve ser dinâmico, vivo, "brincável", explorável, transformável e acessível para todos [7].

Nas Diretrizes Operacionais para a Educação Infantil [11], um dos aspectos normativos tratados é quanto a Espaços Físicos e Recursos Materiais para a Educação Infantil, em que se afirma que os espaços físicos deverão ser coerentes com a proposta pedagógica da 
unidade e com as normas prescritas pela legislação vigente referentes a: localização, acesso, segurança, meio ambiente, salubridade, saneamento, higiene, tamanho, luminosidade, ventilação e temperatura, de acordo com a diversidade climática regional, dizendo ainda que os espaços internos e externos deverão atender às diferentes funções da instituição de Educação Infantil.

Em 2001 foi promulgada a lei que aprovou o Plano Nacional de Educação - PNE [12] e vem somar critérios e parâmetros de qualidade para os espaços físicos da Educação Infantil. Dentre os pontos referentes a "Objetivos e Metas" do Plano, destacam-se dez itens:

De acordo com a Meta $\mathrm{n}^{\circ}$ 2, a exigência de "padrões mínimos de infraestrutura para o funcionamento adequado das instituições (creches e pré-escolas) públicas e privadas, que respeitando as diversidades regionais assegurem o atendimento das características das distintas faixas etárias e das necessidades do processo educativo" [12].

Define ainda na Meta $n^{\circ} 4$ que as instituições já em funcionamento deverão ter seus prédios adaptados, de modo que, até 2006, "todos estejam conformes aos padrões de infraestrutura estabelecidos" [12].

Previsto no Plano Nacional da Educação (PNE) e eleito como uma das prioridades na Conae, o Custo Aluno Qualidade Inicial (CAQi) recomenda quantidades máximas de aluno por turma que considera adequada para o bom andamento da aula [13].

No contexto do CAQi, os padrões mínimos podem ser definidos como aqueles que levam em conta, entre outros parâmetros, os seguintes [14]:

A existência de pessoal de apoio técnico e administrativo que assegure o bom funcionamento da escola, como a preparação da merenda, funcionamento da biblioteca, limpeza predial e setor de secretária da escola, por exemplo.

A definição de uma relação adequada entre o número de alunos por turma e por professor, que permita uma aprendizagem de qualidade.

Nessa proposta, as seguintes relações aluno/professor por turma foram consideradas:

- Creche: 13 crianças,

- Pré-Escola: 22 alunos,

- EF-anos iniciais: 24 alunos,

- EF-anos finais: 30 alunos

Para as escolas nas áreas rurais, na modalidade de escola de Educação do Campo, as referências foram: uma escola para os anos iniciais do Ensino Fundamental com 60 alunos (2 salas e 4 turmas); uma escola para os anos finais do Ensino Fundamental com 100 alunos (2 salas e 4 turmas). A deliberação, contudo, não tem força de lei, nem a legislação brasileira especifica o número de estudantes para cada etapa do ensino. Na prática, cada rede ou escola adota a sua métrica.

Cabe ressaltar que a legislação outorga às esferas estadual e municipal, por intermédio de seus Conselhos de Educação, a responsabilidade de estabelecer critérios e padrões mais específicos para atender e respeitar a especificidade regional.

Não existe uma legislação com critérios e padrões a serem seguidos para construção de unidades escolares. Para este trabalho, utilizaremos as sugestões do CAQi [14], que serviram de base para o Conae 2010. Estas métricas são relevantes para a elaboração de um modelo matemático, pois permitem utilizar estes percentuais no dimensionamento do público alvo do serviço a ser oferecido. A divisão toma por base unidades escolares de Creche (crianças entre 0 e 2 anos), Pré-Escola (crianças entre 3 e 5 anos), EF - Anos Iniciais (contempla do $1^{\circ}$ ano ao $5^{\circ}$ ano, com crianças entre 6 e 10 anos) e EF - Anos Finais (contempla do $6^{\circ}$ ano ao $9^{\circ}$ ano, com crianças entre 11 e 14 anos). O estudo proposto pelo CAQi, propõe modelos de edificações e métricas para cada uma das divisões:

- Creche para 120 crianças (13 crianças por turma), 20 professores em uma área de 915 $\mathrm{m}^{2}$. 
- Pré-Escola para 240 crianças (20 crianças por turma) e 12 professores em uma área de $705 \mathrm{~m}^{2}$.

- $\mathrm{EF}$ - Anos Iniciais para 480 alunos (24 alunos por turma) e 20 professores em uma área de $1.150 \mathrm{~m}^{2}$.

- $\mathrm{EF}$ - Anos Finais para 600 alunos (30 alunos por turma) e 20 professores em uma área de $1.650 \mathrm{~m}^{2}$.

A elaboração das matrizes do CAQi para a modalidade da Educação do Campo, tanto para os anos iniciais como para os anos finais do Ensino Fundamental, levou em conta dois fatores que impactam no Custo Aluno Qualidade Inicial:

a) o tamanho: as escolas do campo são, em geral, pequenas, bem menores do que as urbanas. Essas escolas geralmente não possuem direção própria nem funcionários e, na sua grande maioria, são unidocentes, ou seja, um mesmo professor leciona simultaneamente para alunos de diferentes anos iniciais do Ensino Fundamental;

b) o outro fator, que impacta nos custos fixos, refere-se ao transporte escolar.

As características do prédio para abrigar a oferta de uma escola de Educação do Campo de Ensino Fundamental - anos iniciais, para 60 alunos (15 alunos por turma) e 4 professores, nos anos finais do ensino fundamental a proposta é para 100 alunos ( 25 alunos por turma) e 4 professores.

Não foram incluídas no estudo outras modalidades da Educação Básica, além da escola de Educação do Campo, para as quais, dependendo de sua natureza e de normas específicas, pode ser utilizada referência similar para a construção das respectivas matrizes de padrões mínimos de qualidade [14].

\section{PARAMETROS DO MODELO DE LOCALIZAÇÃO DE ESCOLAS NO MUNICIPIO DE MACAÉ}

Nos últimos anos, tem crescido o número de estudos relacionando os fatores que mais influenciam na qualidade da Educação Básica no Brasil - contemplando creche, pré-escola, ensino fundamental e ensino médio - com a intenção de contribuir e aperfeiçoar as políticas públicas da educação. A educação brasileira é um problema complexo e multifacetado.

Não é apenas a garantia de vagas suficiente nas escolas públicas para possibilitar a educação de crianças e assim assegurar a sua permanência no sistema de ensino. Muitos outros fatores influenciam, tais como: remuneração que garanta alimentação e vestuário, material didático e o transporte até a escola. Sua complexidade abrange desde as questões históricas relacionadas com o tema - o Brasil tem uma dívida social que impacta na qualidade almejada e que se traduz em um claro apartheid de oportunidades educacionais, refletido nos diferentes "Brasis", identificados sob a ótica dos resultados educacionais [3]- até o problema de demanda e oferta de vagas nas unidades escolares, seja na zona urbana ou rural.

Diversas são as questões relacionadas ao deslocamento de alunos para as escolas, muitas delas relacionadas a modelos de Pesquisa Operacional. O desenvolvimento de modelos matemáticos de localização e distribuição representa uma importante ferramenta de aplicação da Pesquisa Operacional (PO). Autores [6], [15], [16], [17], [18], [19] apresentam modelos consolidados de localização de escolas. Como visto em diversos estudos, estes modelos em geral definem parâmetros para o modelo, como capacidade total da unidade escolar, custo, distância etc, porém não discutem os cálculos dos parâmetros do modelo bem como o detalhas operacionais relacionados à situação real de infraestrutura da unidade de escolar.

Para contextualizar o problema é apresentada a caracterização do município de Macaé onde foi realizado o presente estudo, bem como o cálculo dos parâmetros que serão utilizados no modelo de localização de escolas. 


\subsection{MACAÉ}

O município de Macaé é diretamente impactado pelos investimentos da Indústria do Petróleo e gás da Bacia de Campos. A instalação da Sede da Petrobrás tornou o município base de um grande aglomerado petrolífero, diante deste cenário, houve um crescimento acentuado no número de empregos gerados na cidade e região, o que ocasiona uma enorme migração, nesta cidade [20].

Com o crescimento gerado pela exploração de petróleo, a cidade deparou-se com problemas de infraestrutura para atender a crescente população, bem como o deslocamento e o dimensionamento na rede pública municipal. Para minimizar esse ônus causado pelo desenvolvimento, a prefeitura vem trabalhando de forma a atender todas as crianças que chegam juntamente às suas famílias, no município.

De acordo com o Plano Diretor do Município de Macaé, Artigo 42, dentre outras medidas assegura-se:

V - Disponibilizar unidades escolares que atendam aos padrões nacionais da infraestrutura estabelecidos através do Plano Nacional de Educação, conforme preconiza a Lei Federal $n^{\circ} 10.172$, de 09 de janeiro de 2001, utilizando-se do senso educacional para definir prioridades [21].

Em 2014, o município de Macaé contava com 104 escolas de educação infantil e fundamental, divididas em 11 setores, sendo 5 setores (do $7^{\circ}$ ao $9^{\circ}$ setor), localizados na zona rural, com cerca de 36 mil alunos.

Foram coletados dados na Secretaria Municipal de Educação em Macaé, referente a quantidade de alunos, quantidade de docentes e quantidade de pessoal de gestão escolar, de acordo com as sugestões informadas no CAQi. Esses dados são relevantes para a criação de um índice que posteriormente será utilizado no modelo. Os dados dos docentes são divididos em categorias:

- Ensino Infantil: De 0 a 5 anos

- Ensino Fundamental, anos iniciais: do $1^{\circ}$ ano ao $5^{\circ}$ ano

- Ensino Fundamental, anos finais: do $6^{\circ}$ ano ao $9^{\circ}$ ano

- Multisseriada: Refere-se a classes com múltiplos anos, no ensino infantil e fundamental.

- Correção de Fluxo: Refere-se à correção relativa a transferências se profissionais de suas unidades para outras

Para análise no estudo, levaram-se em consideração 92 escolas, das quais 11 estão localizadas na zona rural do município. As escolas pesquisadas são creches, pré-escolas, escolas de ensino fundamental, os dados consolidados estão na tabela 01 , as demais escolas que não foram levadas em consideração, são escolas de ensino médio, e duas ainda não haviam inaugurado no início do ano de 2014. Os dados referentes ao quantitativo de docentes do município de Macaé estão na tabela 02.

\begin{tabular}{|l|r|}
\hline Escolas Urbanas somente c/ Pré Escola & 38 \\
\hline Escolas Urbanas somente c/ Ensino Fundamental & 39 \\
\hline Escolas Urbanas c/ Pré Escola e Ensino Fundamental & 7 \\
\hline Escolas Rurais somente c/Pré Escola & 2 \\
\hline Escolas Rurais somente c/Ensino Fundamental & 1 \\
\hline Escolas Rurais c/ Pré escola e Ensino Fundamental & 7 \\
\hline
\end{tabular}

(Tabela 01 - Quantidade de escolas nas zonas urbanas e rurais) 


\begin{tabular}{|l|r|r|r|}
\hline \multicolumn{1}{|c|}{ Professores } & Referencia & Complementar & Total \\
\hline Ensino Infantil & 690 & 241 & 931 \\
\hline Ensino Fundamental Anos Iniciais & 667 & 211 & 878 \\
\hline $\begin{array}{l}\text { Ensino Fundamental Anos Finais } \\
\text { (incluindo o fluxo de correção) }\end{array}$ & 884 & & \\
\hline Multisseriadas & 6 & 5 & 11 \\
\hline Correção Fluxo & 32 & 25 & 57 \\
\hline Total & 2279 & 482 & 2761 \\
\hline
\end{tabular}

(Tabela 02 - Quantidade de docentes)

Em relação ao quantitativo dos alunos, foram totalizados 33301 alunos de acordo com as divisões apresentadas. A tabela 03 apresenta a quantidade de alunos matriculados no município, nas divisões oferecidas pela Secretaria de Educação. Na tabela 04, apresenta-se a correção de fluxo. Importante ressaltar que em 2014, não existia escola de ensino integral na Zona Rural do município, bem como nos dados levantados, apenas apresentou correção de fluxo no Ensino Fundamental.

\begin{tabular}{|l|c|c|c|c|c|}
\hline Alunos & $\begin{array}{l}\text { Zona } \\
\text { Urbana }\end{array}$ & $\begin{array}{l}\text { Zona } \\
\text { Rural }\end{array}$ & $\begin{array}{l}\text { Ensino } \\
\text { Parcial }\end{array}$ & $\begin{array}{l}\text { Ensino } \\
\text { Parcial/Integral }\end{array}$ & $\begin{array}{l}\text { Ensino } \\
\text { Integral }\end{array}$ \\
\hline Creche & 3117 & 111 & 2108 & 70 & 1050 \\
\hline Pré-Escola & 5132 & 170 & 3544 & 77 & 1681 \\
\hline $\begin{array}{l}\text { Ensino } \\
\begin{array}{l}\text { Fundamental - Anos } \\
\text { Iniciais }\end{array}\end{array}$ & 13983 & 406 & 13639 & 192 & 558 \\
\hline $\begin{array}{l}\text { Ensino } \\
\text { Fundamental - Anos } \\
\text { Finais }\end{array}$ & 10382 & 0 & 10244 & 138 & 0 \\
\hline Total & 32614 & 687 & 29535 & 477 & 3289 \\
\hline
\end{tabular}

(Tabela 03 - Quantidade de Alunos por Divisão)

\begin{tabular}{|l|l|}
\hline Correção de fluxo Ensino Fundamental - Anos Iniciais & 227,00 \\
\hline Correção de fluxo Ensino Fundamental - Anos finais & 278,00 \\
\hline Total & 505,00 \\
\hline $\begin{array}{l}\text { Correção de fluxo Ensino Fundamental - Anos Iniciais, ensino } \\
\text { integral }\end{array}$ & 24,00 \\
\hline Correção de fluxo total & 529,00 \\
\hline
\end{tabular}

(Tabela 04 - Quantidade da correção de fluxo de discentes)

Com os dados levantados sobre construção de escolas padrão no município de Macaé, para a rede pública municipal, apresentam-se os dados na tabela 05. Esses dados foram agrupados com as sugestões do CAQi, porém na planta da edificação constam outros cômodos como Arquivo Permanente, lixo, vestiário, área de serviço entre outros. As edificações modelo são definidas apenas como Educação Infantil e Ensino Fundamental.

\begin{tabular}{|l|c|c|c|c|}
\hline & \multicolumn{2}{|l|}{ Ensino Infantil } & \multicolumn{2}{l|}{ Ensino Fundamental } \\
\hline Descrição & Quantidade & $\mathbf{M}^{2} /$ Item & Quantidade & $\mathbf{M}^{2} /$ Item \\
\hline Salas de aula & 13 & 36,04 & 15 & 42,52 \\
\hline Sala de direção/equipe & 1 & 13,46 & 1 & 13,46 \\
\hline Sala Secretaria & 1 & 25,28 & 1 & 29,81 \\
\hline
\end{tabular}




\begin{tabular}{|l|c|c|c|c|} 
Sala Coordenador & 1 & 13,46 & 1 & 13,46 \\
\hline Sala de professores & 1 & 19,61 & 1 & 19,61 \\
\hline Sala de leitura/biblioteca & 1 & 43,27 & 1 & 43,25 \\
\hline Refeitório & 1 & 145,56 & 1 & 145,56 \\
\hline Cozinha & 1 & 26,82 & 1 & 26,82 \\
\hline Copa & 1 & 7,36 & 1 & 7,36 \\
\hline Pátio coberto & 1 & 323,6 & 1 & 352,93 \\
\hline Parque infantil & 2 & 37,02 & - & - \\
\hline Banheiro de professores & 4 & 6,57 & 4 & 6,57 \\
\hline Banheiro de crianças & 2 & 30,17 & 2 & 30,17 \\
\hline Sala de depósito & 1 & 16,96 & 3 & 16,96 \\
\hline Parque infantil & 1 & 10 & 1 & 20 \\
\hline Auditório & - & - & 1 & 100 \\
\hline $\begin{array}{l}\text { Laboratório } \\
\text { informática }\end{array}$ & 1 & 43,27 & 1 & 43,27 \\
\hline \multicolumn{1}{|c|}{ Total } & \multicolumn{2}{|c|}{2029,87} & 2070,79 \\
\hline
\end{tabular}

(Tabela 05 - Descrição das áreas correspondentes às unidades escolares)

Com essas informações, os seguintes índices foram criados, na tabela 06 apresenta-se a quantidade alunos por professor na rede municipal, nas categorias de professores referência e professores complementares.

\begin{tabular}{|l|r|}
\hline Alunos p/ professor Ensino infantil - Referencia & 12,08215 \\
\hline Alunos p/ professor Ensino infantil - Complementar & 33,71541 \\
\hline Alunos p/ professor Ensino Fundamental - Referencia & 36,26793 \\
\hline Alunos p/ professor Ensino Fundamental - Complementar & 110,58482 \\
\hline
\end{tabular}

(Tabela 06 - Relação alunos por professor nas categorias Referência e Complementar)

Em relação a infraestrutura padrão, partindo do pressuposto que todas as 98 escolas da rede pública municipal tivessem a dimensão padrão, o total de escolas em relação a quantidade de alunos é descrita pela tabela 07

\begin{tabular}{|l|l|l|}
\hline & Zona Urbana & Zona Rural \\
\hline Alunos Ensino Infantil & 8249 & 281 \\
\hline Salas Ensino Infantil Ensino & 412 & 14 \\
\hline $\begin{array}{l}\text { Escolas Padrão Ensino } \\
\text { Infantil }\end{array}$ & 24365 & 1 \\
\hline $\begin{array}{l}\text { Alunos } \\
\text { Fundamental Fundamental }\end{array}$ & 812 & 406 \\
\hline Salas Ensino Fundão Ensino & 54 & 14 \\
\hline $\begin{array}{l}\text { Escolas Padráo } \\
\text { Fundamental }\end{array}$ & 1 \\
\hline
\end{tabular}

(Tabela 07 - Quantidades de escolas-padrão necessárias para atender à necessidade) 


\subsubsection{Modelo Macaé}

Com posse das informações, tornou-se possível criar um modelo inicial, posteriormente será possível adaptar aos indicadores e métricas que venham a ser utilizados.

$$
\begin{array}{ll}
\text { 1. } & \text { Min } \sum_{i=1}^{n} \sum_{j=1}^{m} C_{i j} X_{i j} \\
\text { Sujeito a } \\
\text { 2. } & \sum_{j} x_{i j}=d_{i} \forall i \\
\text { 3. } & \sum_{j} x_{i j} \leq \operatorname{Cap}_{j} \times y_{j} \forall j \\
\text { 4. } & \sum_{j} y_{j}=P \\
\text { 5. } & x_{i j} \geq 0, y_{i} ; \in\{0,1\}
\end{array}
$$

Índices,

$\circ \quad{ }_{i}=\{1,2,3 \ldots n\}:$ pontos de demanda

Parâmetros

○ $\quad j=\{1,2,3 \ldots \mathrm{m}\}$ : locais possíveis

$$
\begin{array}{ll} 
& d_{i}: \text { demanda dos centróides } \\
\circ & \text { Cap } \\
\text { : Capacidade da escola } \\
\circ & c_{i j} \text { : distancia de i para } \mathrm{j} \\
\circ & P \text { : números de escolas }
\end{array}
$$

- $X_{i j}$ : Quantidade de alunos $i$ alocados em $j$

○ $y_{j}:\left\langle\begin{array}{l}1 \\ 0\end{array}\right\rangle$ Se construir (1) Caso contrário (0)

Em um modelo clássico de programação linear/inteira, para localização de escolas utiliza-se a função-objetivo definida em (1). As restrições (2), (4) asseguram que cada nó é designado a apenas uma mediana. A restrição (3) determina que as capacidades das escolas devem ser respeitadas de acordo com a quantidade de escolas existentes, e a restrição (5) corresponde à condição de binariedade das variáveis.

Para a elaboração do modelo, os seguintes parâmetros são considerados:

- Demanda: é dada ao nível de setor censitário e representa a população na faixa etária que demanda uma unidade escolar. Cada setor censitário é representado localmente por um centroide, que servirá para definir as distâncias às escolas.

- Distancia: Gera a matriz distancia ou pela distância euclidiana ou pelo percurso gerado do centro de massa a unidade escolar. Na figura 2, é possível verificar parte dos setores censitários, nessa imagem também estão representadas as retas traçadas a partir da distância euclidiana. Na figura 3, estão representadas as distâncias feitas através da delimitação de um percurso;

- Capacidade das escolas: dada em número de crianças que serão atendidas, porém para um gestor um número de alunos não tem um significado real dessa demanda, nesse caso deve ser utilizado os parâmetros calculados acima pelas tabelas 6 e 7. Como, por exemplo, se o modelo de programação matemática desse que no local $j$ um atendimento de uma demanda de 300 alunos significa o desdobramento em diversos outros parâmetros, observados na tabela 8 . 


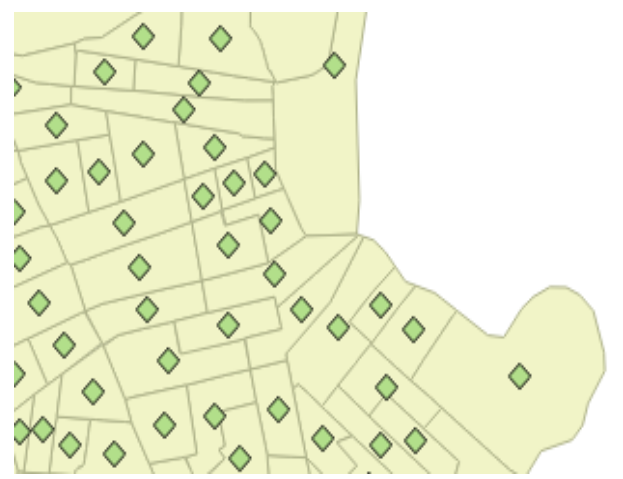

(Figura 1 - Setores Censitários de Macaé)

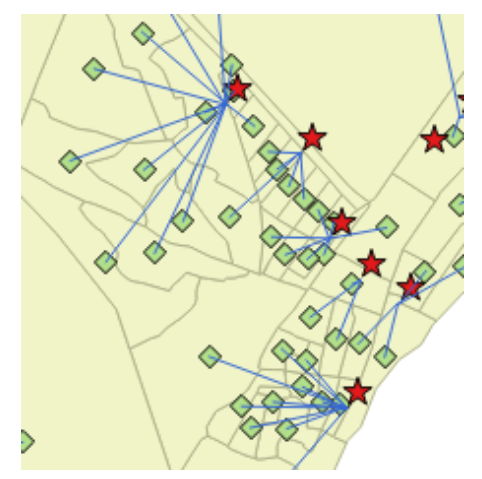

(Figura 2 - Ligação entre os setores censitários e as escolas por distância euclidiana)

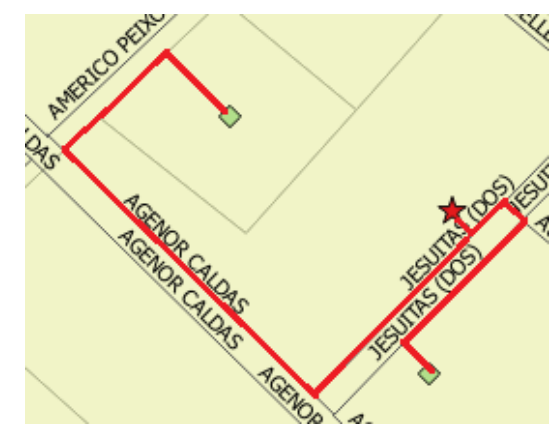

(Figura 3 - Ligação entre os setores censitários e as escolas através de um percurso definido)

\begin{tabular}{|l|c|c|}
\hline & $\begin{array}{l}\text { Ensino } \\
\text { Infantil }\end{array}$ & $\begin{array}{l}\text { Ensino } \\
\text { Fundamental }\end{array}$ \\
\hline Salas de & 15 & 10 \\
\hline $\begin{array}{l}\text { Professores } \\
\text { Referencia }\end{array}$ & 25 & 8 \\
\hline $\begin{array}{l}\text { Professores } \\
\text { Complementares }\end{array}$ & 9 & 3 \\
\hline $\begin{array}{l}\text { Área total das } \\
\text { salas em m }{ }^{2} \text { total }\end{array}$ & 540,6 & 425,2 \\
\hline $\begin{array}{l}\text { Área } \\
\text { edificada em m }\end{array}$ & 1459,74 & 1920,16 \\
\hline
\end{tabular}

(Tabela 08 - Relação entre parâmetros calculados, visando atender duas unidades escolares de Ensino Infantil e Fundamental com capacidade de 300 alunos)

\section{DISCUSSÃO E CONCLUSÃO}

Educação é a palavra de ordem para o futuro, mais que uma necessidade ela é um direito. Devido a sua importância na formação do cidadão, diversas medidas, sugestões, leis e diretrizes foram criadas.

Porém, o Brasil, ainda está engatinhando no que tange ao cumprimento dessas normas da forma mais confortável e plausível para os alunos, principalmente aos pequenos ainda na fase do Ensino Infantil. As sugestões e deliberações existem, mas não a obrigação da lei na qual os estados e municípios devem oferecer aos jovens estudantes o que eles merecem: um espaço justo, organizado, respeitando tanto a individualidade do aluno, quanto a presença do professor. Sabe-se que existem escolas apresentando superlotações, professores sobrecarregados e a educação tão primordial, passa negligenciada por falta de estrutura básica. 
Para este trabalho, utilizou-se as sugestões do CAQi, que serviram de base para o Conae 2010. Estas métricas são relevantes para a elaboração de um modelo matemático, pois permitem utilizar estes percentuais no dimensionamento do público alvo do serviço a ser oferecido. Esse primeiro modelo apresentado será base da construção de modelos mais complexos e que levarão em conta as relações encontradas e os estudos sugeridos pelo governo.

$\mathrm{O}$ atual modelo Macaé tem como objetivo minimizar a distância dos pontos de demanda para os locais possíveis de unidades escolares, assegurando que cada aluno é designado a apenas uma escola, sendo a capacidade das escolas respeitadas de acordo com a quantidade de escolas existentes. Posteriormente o modelo será melhorado com os dados levantados nesse estudo e em outros mais aprofundados. Durante o levantamento de dados para a realização do estudo pode-se verificar que a zona urbana conta com uma quantidade maior de alunos, por isso demanda mais unidades escolares, porém na zona rural, encontra -se o problema das grandes distâncias e poucos alunos, o que torna a distribuição por distância um desafio real e complexo.

Este trabalho está passível a erro, visto que seus dados foram consolidados manualmente referentes ao ano de 2014, algumas escolas foram inauguradas e a redistribuição dos alunos na rede pública municipal também mudou. O intuito deste trabalho é fazer uma análise dos dados e a partir do obtido, novos estudos aprofundados, bem como sugestões poderão ser feitas posteriormente.

\section{REFERÊNCIAS BIBLIOGRÁFICAS}

[1] KUPPER, Agnaldo. Educação Brasileira: Reflexões E Perspectivas. Revista Terra E Cultura, Ano XX, No 39. Londrina, 2004.

[2] SCHWARTZMAN, Simon. Os desafios da educação no Brasil. São Paulo: 2002. Disponível em: < http://www.schwartzman.org.br/simon/desafios/1desafios.pdf>. Acesso em: fev 2014

[3] BRASIL. Ministério da Educação. Conselho Nacional de Educação. Câmara da Educação Básica. Resolução n. 2, de 7 abril de 1998. Estabelece normas para aplicação do inciso IX do artigo $4^{\circ}$ da Lei no 9.394/96 (LDB), que trata dos padrões mínimos de qualidade de ensino para a Educação Básica pública. Brasília, 2010. Disponível em: < portal.mec.gov.br>. Acesso em: mar. 2015

[4] BANCO MUNDIAL.Achieving World Class Education in Brazil: The Next Agenda. Human Development Sector Management Unit and Latin America and the Caribbean Regional Office. December 21, 2010, 2010b. Disponível em: $<$ http://portal.mec.gov.br/index.php?option=com_content\&view=article\&id=16156 $>$ Acesso em jan 2015.

[5] IGNACIO, A. A. V. ; FERREIRA FILHO, V. J. M. ; SAMPAIO, L.M.D . Eficiência dos recursos públicos das cidades produtoras de petróleo e derivados através da DEA em comparação com o índice Firjan. São Paulo. In: XXI SIMPEP, 2014

[6] BARCELOS, F. B; PIZZOLATO, Nélio; LORENA, Luiz Antonio. Localização de escolas do ensino fundamental com modelos capacitado e não-capacitado: caso de vitória/es. Pesqui. Oper. , vol.24, n.1, pp. 135-149, 2004.

[7] BRASIL. Ministério da Educação. Secretaria de Educação Básica. Parâmetros Básicos de Infra-estrutura para Instituições de Educação Infantil. Brasília : MEC, SEB, 2006. Disponível em: http://portal.mec.gov.br/seb/arquivos/pdf/Educinf/miolo_infraestr.pdf>. Acesso em: mar. 2015 
[8] SANTOS, Ana Carolina. ESTUDO DE LOCALIZAÇÃO DE ESCOLAS PÚBLICAS EM ÁREAS URBANAS. Dissertação (Mestrado) - Programa De Pós-Graduação Em Transportes, da UNB. Brasilia, 2012.

[9] LOBO, Debora. Dimensionamento e otimização locacional de unidades de educação infantil. Dissertação (Mestrado) - Programa De Pós-Graduação Em Engenharia De Produção, da UFSC, Santa Catarina, 2003.

[10] BRASIL.Lei $\mathrm{n}^{\circ} 11.274$, de 6 de fevereiro de 2006. Altera a redação dos artigos 29, 30, 32 e 87 da Lei $n^{\circ} 9.394$, de 20 de dezembro de 1996, que estabelece as diretrizes e bases da educação nacional, dispondo sobre a duração de 9 (nove) anos para o ensino fundamental, com matrícula obrigatória a partir dos 6 (seis) anos de idade. Diário Oficial da União, Poder Legislativo, Brasília, DF, ano 143, n. 27, 7 fev. 2006. Seção 1, p. 1-2. Disponível em: <http://www.presidencia.gov.br/legislacao>. Acesso em: mai. 2014

[11] BRASIL. Ministério da Educação. Conselho Nacional de Educação. Câmara de Educação Básica.Parecer $n^{\circ}$ 04, de 06 de setembro de 2000. Parecer Normativo sobre as diretrizes operacionais para a Educação Infantil.

[12] BRASIL. Plano Nacional de Educação. Apresentado por Ivan Valente. Rio de Janeiro: DP\&A, 2001

[13] REVISTA EDUCAÇÃO. Salas Cheias. Jan de 2015. Disponível em: < http://revistaeducacao.uol.com.br/textos/213/salas-cheiasapesar-das-dificuldades-emdeterminar-a-quantidade-ideal-de-335577-1.asp> Acesso em mar 2015

[14] BRASIL. Ministério da Educação. Conselho Nacional de Educação. Câmara da Educação Básica. Resolução n. 2, de 7 abril de 1998. Estabelece normas para aplicação do inciso IX do artigo $4^{\circ}$ da Lei n ${ }^{\circ}$ 9.394/96 (LDB), que trata dos padrões mínimos de qualidade de ensino para a Educação Básica pública. Brasília, 2010. Disponível em: < portal.mec.gov.br>. Acesso em: mar. 2015

[15] ANTUNES, Antonio; PEETERS, Dominique. On solving complex multi-period location models using simulated annealing. European Journal of Operational Research 130 (2001) $190-201$.

[16] PIZZOLATO, N.D. \& Silva, H.B.F. (1993). Proposta Metodológica de Localização de Escolas: Estudo do Caso de Nova Iguaçu. Pesquisa Operacional, 14, 1-13.

[17] PIZZOLATO, N.D. (1994). A Heuristic for Large-Size p-Median Location Problems with Application to School Location. Annals of Operations Research, 50, 473-485.

[18] PIZZOLATO, Nélio; BARROS, Ana Glaúcia; BARCELOS, Fabrício; CANEN, Alberto. Localização de escolas públicas: síntese de algumas linhas de experiências no Brasil.. Pesqui. Oper, vol.24, n.1, pp. 111-131. 2014.

[19] PIZZOLATO, Nélio; MENEZES, Rafael . Application of the capacitated p-median and maximal covering location models. Pesquisa Operacional (2014) 34(2): 301-317.

[20] IGNACIO, A. A. V.; MOURA, Luize de Magalhães; SAMPAIO, Léa Maria Dantas; "Uso Da Simulação De Monte Carlo Em Projetos De Construção De Rodovias No Norte Fluminense". In Anais do XVII Simpósio de Pesquisa Operacional e Logística da Marinha - SPOLM 2014

[21] MACAÉ. Lei Complementar $\mathrm{N}^{\circ} 076 / 2006$. Plano Diretor.2006. Disponivel em < www.macae.rj.gov.br/midia/conteudo/arquivos/1272969995.pd $>>$ Acesso em Mar. 2015 